\title{
Utilizing Wikispaces as a Learning and Knowledge Tool -Sharing Environment for Post-Graduate Students in a Medical Library and Information Science Program of Study
}

\author{
Vahideh Zarea Gavgani and Faranak Kazemi Majd \\ Faculty of Para-Medicine, \\ Tabriz University of Medical Sciences, Tabriz-Iran \\ vgavgani@gmail.com; Kazemi.majd@yahoo.com
}

\begin{abstract}
Background and Objectives of study: Wikis are collaborative and interactive tools used in sharing, teaching, learning and publication. The main objectives of this study are (1) to identify Wikispace's applicability as an educational tool to improve students' active contribution in educational activities and (2) to find out Wikispaces potential for knowledge sharing (brain storming, problem solving) through discussion.

Methodology: We developed a virtual class in wikispaces.com for postgraduate students of Medical Library and Information Science during first semester of the academic year 2011-2012, from the months October to December (Mehr-Day 1390-1391 in Persian Calendar). All 9 students were invited to wikispaces and they are taught about using and interacting with Wiki. They are asked to use wiki to communicate with classmates and with teacher. In the mid semester questionnaire distributed to collect students self-reporting evaluation about wiki. Also, students' collaboration in sharing knowledge, class activities, utilizing wiki for different purposes was evaluated through an educational audit checklist.

Results: All students were unfamiliar with wikispaces and started using wiki for first time. All the students $(100 \%)$ were positive about wikispaces and found it enjoyable learning tool.
\end{abstract}

Keywords: web 2.0, wiki, wikispaces, e-Learning, classroom, knowledge sharing, knowledge transfer

\section{Introduction}

A wiki is a website developed collaboratively (dictionary.com,) that can be modified or contributed by users (Britannica, 2012) using a simplified markup language (Wikipedia, 2012). Wikis

Material published as part of this publication, either on-line or in print, is copyrighted by the Informing Science Institute. Permission to make digital or paper copy of part or all of these works for personal or classroom use is granted without fee provided that the copies are not made or distributed for profit or commercial advantage AND that copies 1) bear this notice in full and 2) give the full citation on the first page. It is permissible to abstract these works so long as credit is given. To copy in all other cases or to republish or to post on a server or to redistribute to lists requires specific permission and payment of a fee. Contact Publisher@InformingScience.org to request redistribution permission. are objective for collaboratively sharing and transferring information and knowledge. Easy to develop, easy to access and interactive nature of Wiki has made it an effective tool for organization of the teaching / learning activities; student and teacher contribution; and evaluate the involvement of each member in educational process. There are many version of wikis can be used for education and communicational pro- 
poses (Catalina PASCU, 2009). E-Learning facilities and tools has influenced in peoples' preference in way of leaning. Today people especially postgraduates and academia tend to acquisition rather than education comparing with longstanding programmed educational system. They like to learn and practice special subject and skills pragmatically in a virtual electronic/online environment rather than a physical space and assigned time. In online environment, learners have different choices for how to learn, where to learn, what to learn. They tend to learn and practice subject matters utilizing variety of online, interactive, collaborative tools and environment every time they may like and every place they may choose. Web 2.0 applications facilitate such learning and familiarization. Web2.0's "architecture of participation" (O'Reilly, 2005) provides an environment for learning and teaching that is much more appropriate for active and interactive participation and knowledge sharing. In health science also using wikis for education proliferated.

\section{Review of Literature}

A review of literature published in Pub med on wiki in medicine and health science showed that, wiki is used for various purpose such as problem solving (Massar, Travers, Elhai, \& Shrager,2005; Casla \& Zubiaga, 2010), documentation (Harris \& Zeng, 2008), and case study, journal club, evidence based learning in electronic environment. A study entitled " to implement and evaluate the impact of an elective evidence-based medicine (EBM) course on student performance during advanced pharmacy practice experiences (APPE)", using a Pre- and post tests found that students improved on $83 \%$ of the core evidence-based medicine concepts evaluated (Bookstaver et al. , 2011). Archambault et al. (2010) Surveyed 50 healthcare professionals $(25$ physicians and 25 allied health professionals) working in the emergency departments of three trauma centers in Quebec, Canada using interview to find out their intention on using wiki to promote reminder in cancer care.

\section{Design of Study}

Wikispaces holds all the features of a physical class such as question/ answering, involvement in discussions, problem solving, and putting forward new ideas in electronic and online environment but excludes the barriers of fixed time and place, which are known as dominant obstacles of physical classes.

Before utilization of web2.0 tools become prevalent among public and professionals, the educational behavior of teaching and learning limited to in person contact communication. Web and web based communications created a new teaching and learning model in which the long standing a one way communication could be developed in electronic environment using email and website. But in comparison with the email communication, the application of web 2.0 tools created a really simple and collaborative environment in which educators and learners could communicate more interactively, more rapidly and more easily. To mimic library service revolution offered by Gavagni and Mohan (2008), here we differentiae the three above mentioned era in educational system into three models including: conventional, neo-conventional and none conventional models.

Conventional model: In conventional model in person contact was necessary in teaching and learning. Teaching had to be done in a special space at regulated times, course material introduced to class and learners had to return the assignments to teacher (only to teacher) in class at the next session or at teachers' office. The limited time of class and the one way /parental teaching model was not suitable for brain storming. Audit of students' activities and involvement is recorded in each session using worksheet or notebooks.

Neo-conventional model: In the neo-conventional model using web tools like website and email address a mixed model of e-learning and traditional learning can be observed in regular teacher- 
student communication. But still there are many limitations and replications as well as inconsistencies in the processes. For example here is a scenario for teacher-student relationship in neoconventional model.

Teacher creates a web site and an email ID to introduce course objectives, materials and assignments to all learners once at the beginning of each semester. He/she asks students to submit assignments to herlhis email ID. S/he reminds the class that they are allowed to call or email in case they have question about course. Learners had to individually send the assignments, questions to teacher's email box and then they received the answer through the same channel if the question wont buried up in the mailbox. Teacher wants to open a discussion and make the students to solve the problem through brain storming. The one way channel of neo-conventional model does not provide such interactive opportunity for brain storming. To evaluate the students' individual activities and involvements in class, teacher must stick to the notes s/he may take in class trough observation.

Non-Conventional model: Educators and learners work collaboratively, share information and transfer knowledge in totally information and communication technology (ICT) based environment. They have equitable access to information; they simultaneously contribute in talks and discussion. They can modify, edit and add comments not only as creator but also as audience and consumer. It is possible using web2.0 and social networking tools and second life. All the individual activities are recorded by date and time automatically.

We utilized wikispaces as an educational tool to improve post graduate students of medical library and information sciences students' involvement in learning, and sharing knowledge within class.

\section{Setting}

This study was done in a post graduate level i.e. master lever students of medical library and information sciences with 9 students. The average age of students was 22 years old. The virtual/eclass was hold in the first semester of the academic year starting from October 2011 to January 2012. The questionnaires were disseminated to class after the mid semester, after two months. The educational audit questionnaire filled in by teacher using wikispaces automatic records at the end of class.

\section{Methodology}

The study is basically a descriptive study. We developed a virtual class in wikispaces.com for postgraduate students of Medical Library and Information Science during first semester of the academic year 2011-2012 during the months October to December (Mehr-Day 1390-1391 in Persian Calendar). Total number of 9 students formed our small group class universe. First of all wikispaces was introduced to students. Then they were invited to wikispaces and they were taught about using and interacting with Wiki. Students were unfamiliar with wikispaces and started using wiki for first time. They were asked to use wiki for communicate with class mates and with teacher. Questionnaire was used to pull up students' attitude toward wikispaces. Educational audit checklist was used to assess students' collaboration in sharing knowledge, class activities, utilizing wiki for different purposes. Data were analyzed using simple descriptive analysis methods in SPSS.

\section{Result}

The main objectives of this study were to identify the Wikispace's applicability as an educational tool to improve students' active contribution in educational activities. And, Wikispaces potential 
for knowledge sharing (brain storming, problem solving) through discussion section of wiki. Total number of 9 post graduate students participated in this study. The average age of participant was 22 . The study found that $100 \%$ of participants are positive about using wikispaces as an educational tool and they all enjoyed keeping with class through wikispaces.

Total number of participants $(100 \%)$ stated that they have used wiki for Uploading/Downloading class materials and assignments (Figure 1). Again all of the participants (100\%) stated that they have found wiki as an appropriate tool for education because of its capacity to make the class materials accessible, any time and any place. They all believed that wiki created competency among students to participate in class activities. Majority (99\%) stated that wiki makes teacher available and contactable even out of class time during week monitoring the wiki and responding to questions all updating the discussions. However, just 77\% referred to educator's presence through monitoring and concluding the discussions $n$ wiki. Majority (99\%) said that they have learnt from discussions put forward in wikispaces. And $77 \%$ believed that discussion part encourage them to share knowledge.

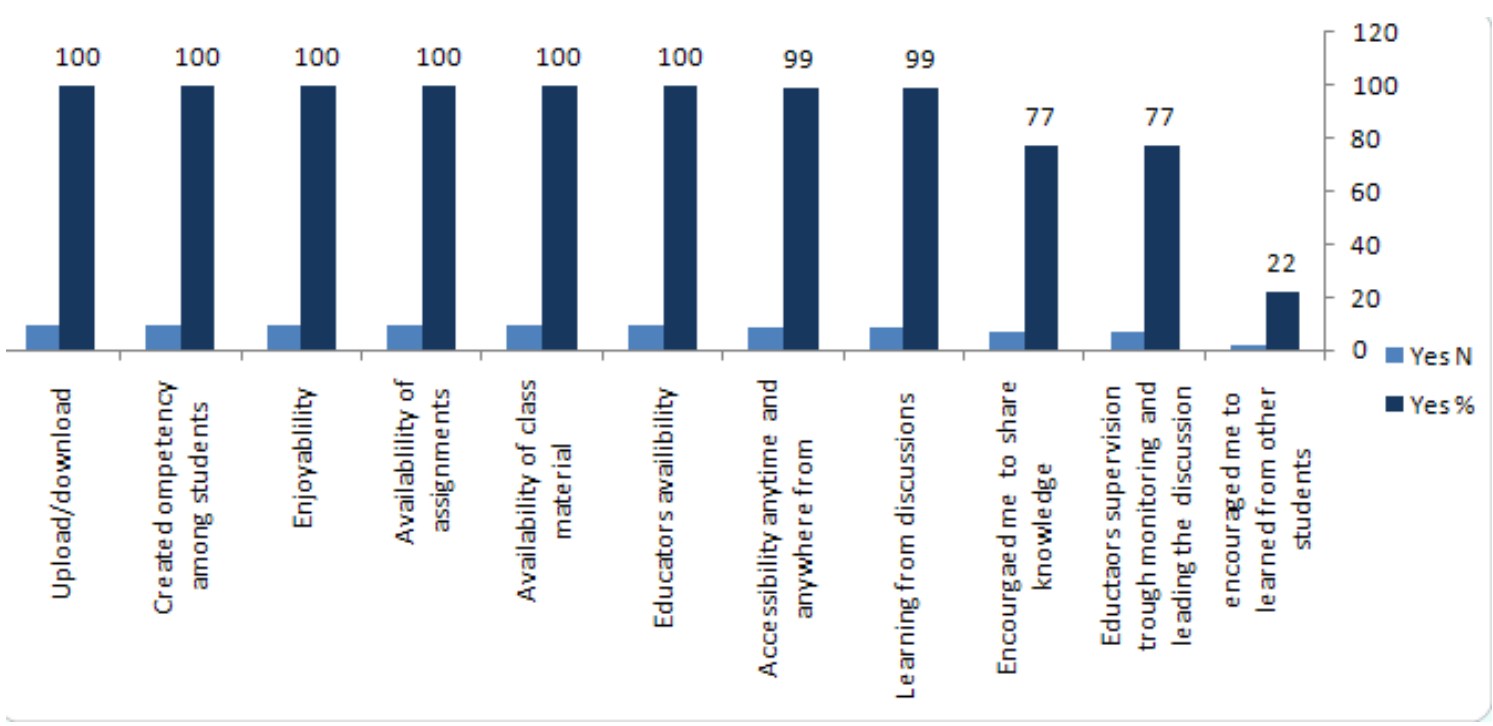

Figure 1 student's attitudes towards using wiki

We also asked students to openly express their opinion about the questions on what was their best and worst experience in wikispaces for this class, what was the most used and most useful thing in wikispace-based class? A question also was asked about limitation they may have had faced with wikispaces? Table 1 shows the questions and answers for this purpose. 
Table 1 Open Questions and Answers on the best and worst with wikispaces

\begin{tabular}{|l|l|}
\hline Question & Answer \\
\hline $\begin{array}{l}\text { What is the best thing/feature of wikispaces for } \\
\text { this class? }\end{array}$ & $\begin{array}{l}\text { Most of them stated that access to class materi- } \\
\text { als any time and any place is the best feature } \\
\text { because make it easy to keep up with class. } \\
\text { Also its collaborative environment is enjoyable } \\
\text { and they can share information easily, also it is } \\
\text { good because is a new experience. }\end{array}$ \\
\hline $\begin{array}{l}\text { What is the worst thing/feature of wikispaces } \\
\text { for this class? }\end{array}$ & $\begin{array}{l}\text { It is not possible to send something confiden- } \\
\text { tial, it is not searchable. }\end{array}$ \\
\hline What is the most used feature of wikispaces? & $\begin{array}{l}\text { Used to Upload and download materials, dis- } \\
\text { cussion }\end{array}$ \\
\hline What is the most useful feature of wiki? & Discussion, recent change, sharing nature \\
\hline What is the limitation with wiki & $\begin{array}{l}\text { Not searchable, Internet access and disconnec- } \\
\text { tion }\end{array}$ \\
\hline
\end{tabular}

\section{Evaluation of Wikispaces as a Virtual Classroom}

Educational audit Identify strengths, weaknesses, opportunities and threats (SWOT) (NHS, 2011). According to the SWOT we built a set of questions to evaluate the effectiveness of wikispaces in improving activities and participation of students in class through wikispaces. Table 2 shows the set of Audit Questions for this purpose:

\section{Table 2 Wikispaces Audit questionnaire}

\begin{tabular}{|l|}
\hline Each student has at least one free post \\
\hline Each student has contributed in each discussion one or more time \\
\hline Each student has submitted assignment of each session regularly \\
\hline Each student has used email to send message to other students \\
\hline Each student has used email to send message to educator \\
\hline Each student has used notify me \\
\hline Each student has used RSS \\
\hline
\end{tabular}

Total number of students (100\%) participated in class activities using files (up load and download) features and submitted assignments for each session regularly. Figure 2 shows the results of this audit. 


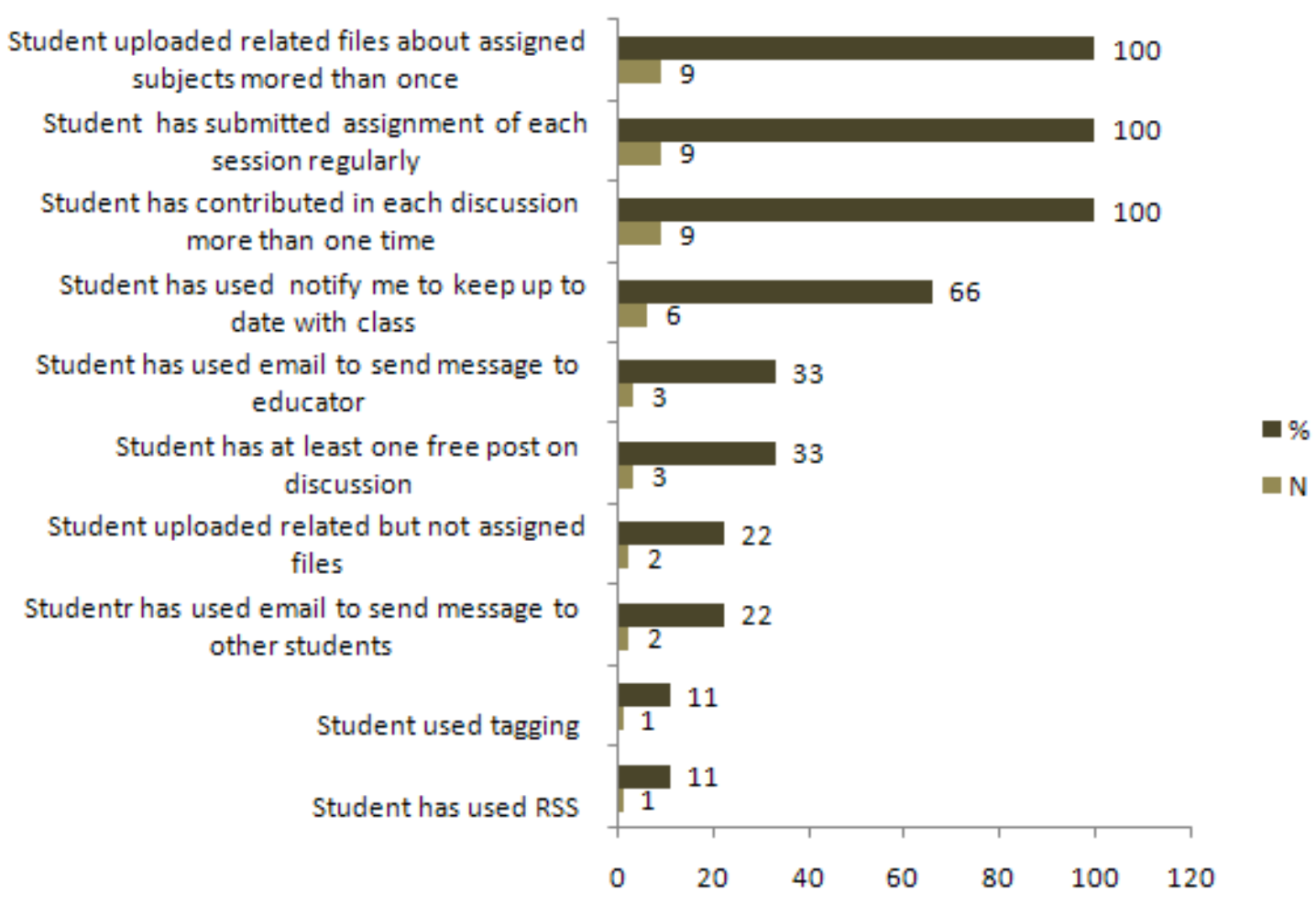

Figure 2 Wikispaces' Audit Result

All of the students $(100 \%)$ participated in discussions (brain storming and transferring knowledge) by more than one reply for each discussion. Out of students $66 \%$ used Notify Me feature of wiki to keep up to date, $33 \%$ used email feature to send personal message to other members. The lowest used features were tagging and RSS feeds.

\section{Discussion and Conclusion}

This study was conducted in a small group post graduate level class i.e. Master of medical library and information science. The courses thought through wiki were Information Science and Management of information centers and libraries focused on total quality management. The objectives of study were to find out Wikispace's applicability as an educational tool to improve students' active contribution in educational activities and Wikispace's potential for knowledge sharing (brain storming, problem solving) through discussion. The study found that Wikispaces is an education tool to improve student's active participation and interaction in class. It's online and easy to access and always available feature makes it good for educators and learners to have a highly connected networking learning environment. The studies conducted preciously among different users (Bray, 2011; Catalina PASCU, 2009) recognized the same qualities for wiki's applicability in education. This study also found that students were not already familiar with wiki and they used this application for first time in this class, therefore they found it interesting. The study of Bray (2011) among teachers also found the similar results. This indicates that increasing development of new information technology applications specially web 2.0 tools for teaching and collaborations needs more informing about their features among academic users. Without familiarity most of these applications remain less used. Most significant feature of wikispaces is its integrated environment. It enables educators and learner to have all material and communicated contents in one place to track them, to evaluate, judge, to reorganize and re-disseminate. Controlling, monitoring and management of activities is very easiest than using email, neo-conventional model. 
Despite of accessible nature of wiki because of internet access problem most of the time users face problem in using collaborative tools on web 2.0.

\section{Limitations of Study}

The object of study is only nine students, which is too small a sample to make findings and conclusion representative.

\section{References}

Archambault, P.M., Légaré, F., Lavoie, A., Gagnon, M. P., Lapointe, J., St-Jacques, S., Poitras, J., Aubin, K., Croteau, S., \& Pham-Dinh, M. (2010). Healthcare professionals' intentions to use wiki-based reminders to promote best practices in trauma care: A survey protocol. Implementation Science, 5(45). Retrieved from http://www.implementationscience.com/content/5/1/45

Bookstaver, P.B., Rudisill, C. N., Bickley, A. R., McAbee, C., Miller, A. D., Piro, C. C., \& Schulz, R. (2011). An evidence-based medicine elective course to improve student performance in advanced pharmacy practice experiences. American Journal of Pharmaceutical Education, 75(1), 9.

Bray, R. (2011). Measuring the use of the sumer tech integration wiki among district teachers and the functionality of its design. Master Science Degree thesis, submitted to Southern Connecticut State University.

Casla, A. V. \& Zubiaga, I. S. (2010). Paternity testing in a PBL environment. Biochemistry and Molecular Biology Education, 38(1), 37-42. doi: 10.1002/bmb.20367.

Catalina PASCU, O. (2009). Examples of good practice wikis case studies: Prahova. Presented in the $5^{\text {th }}$ International Scientific Conference, E-Learning and Software for Education, Bucharest, April 9-10, 2009

Dictionary.com (2012) wiki. Available at http://dictionary.reference.com/browse/wiki

Encyclopedia Britannica. (2012).wiki. Available at : http://www.britannica.com/EBchecked/topic/1192819/wiki

Gavgani, V. Z., \& Mohan, V. V. (2008). Application of web 2.0 tools in medical librarianship to support medicine 2.0. Web logy, 5(1), Article 53. Available at: http://www.webology.org/2008/v5n1/a53.html

Harris, S.T., \& Zeng, X. (2008).Using wiki in an online record documentation systems course. Perspectives in Health Information Management, 30(5), 1.

Massar, J.P., Travers, M., Elhai, J., \& Shrager, J. (2005). BioLingua: A programmable knowledge environment for biologists. Bioinformatics, 21(2), 199-207.

NHS foundation Trust. (2011). Placement details (Section J) \& educational audit for 'practice-based' assessed modules and programmes. Available atwww.lau.org.uk/training/forms

O'Reilly, T. (2005). What is web 2.0? Retrieved from O'Reilly http://oreilly.com/web2/archive/what-isweb-20.html

Sendall, P., Ceccoucci, W., \& Peslak, A. (2008). Web 2.0 matters: An analysis of implementing web 2.0 in classroom. Information Systems Education Journal, 6(64). Available at http://isedj.org/6/64

Wikipedia. (2012) . Wiki. Available at http://en.wikipedia.org/wiki/Wiki 


\section{Biographies}

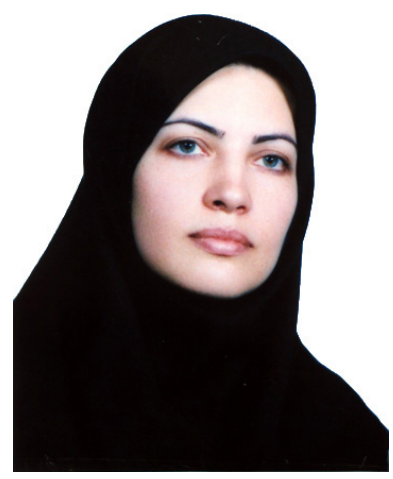

Dr. Vahideh Zarea Gavgani is a medical information specialist. She is an assistant professor and academic staff member of Tabriz University of Medical Science in Department of Medical Library and Information Science (Iran). Member of International Review Board with International Journal of User Driven Health Care, Scholarly journal of Bojnord University of Medical Science and Journal of Health Management . Committee Member of Iranian Center for Evidence Based Medicine (ICEBM), Committee member of Clinical Governance Programme in Tabriz University of Medical Sciences (Iran) and Academic Staff Member of Research Development and Coordination Center (RDCC). She has also worked as head of Medical Library of Tabriz University for more than 4 years and Committee Member of an International Conference on Evidence Based Library and Information Practice. She has published and presented more than 50 papers in international, national books, journals and conference; three books written and one translated into Farsi. Her topics of interest are consumer health information, Information Therapy, Patient Information, Evidence Based Practice, Web 2.0, Information storage and retrieval and information science.

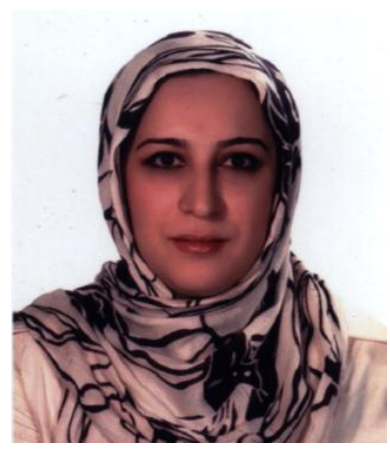

Faranak Kazemi Majd is a post graduate student and research scholar in Department of Medical Library and Information Science. She has translated a book, and plenty of articles from English language into Persian in different subjects. Her topics of interest include e-learning, web 2.o, English Language writing, Adding value to information for Information Literacy such as translation, summarizing and simplifying to promote readability for general public and patients. 